International Journal of Advanced Chemistry, 9(2)(2021) $192-195$
International Journal of Advanced Chemistry
SPC
Website: www.sciencepubco.com/index.php/IJET
Research paper

\title{
Production and characterization of metallurgical coke from duduguru coal
}

\author{
Nasirudeen M. Baba ${ }^{1 *}$, Yusuf Zubairu ${ }^{1}$, Jude C. Onwuka ${ }^{2}$ and Ahmad A. Ambi ${ }^{3}$ \\ ${ }^{1}$ Department of Chemistry, Federal University of Lafia, P.M.B 146, Lafia, Nasarawa State, Nigeria \\ ${ }_{2}^{2}$ Department of Science Laboratory Technology, Federal University of Lafia, P.M.B. 146,Lafia Nasarawa State Nigeria \\ ${ }^{3}$ Department of Science Laboratory Technology, Federal Polytechnic Bauchi, P.M.B. 0231,Bauchi, Bauchi State Nigeria \\ *Corresponding author E-mail: nasirudeenbaba@gmail.com
}

\begin{abstract}
This work illustrates the production and characterization of metallurgical coke from Duduguru coal, Obi local Government Area of Nasarawa State, Nigeria. The analytical assessment of properties such as proximate analysis, elemental composition, and calorific value are very important to know the coking qualities of the coal. The proximate analysis showed that the moisture content, ash content, volatile matter, fixed carbon and calorific values of the coal are; $1.86 \%, 18.82 \%, 43.74 \%, 53.58 \%$ and $5405.15 \mathrm{Cal} / \mathrm{g}$ respectively. Based on the result of the proximate analysis, the coal is of good metallurgical coke quality from an industrial prospective and heat generation is to be considered. Elemental analysis shows that due to the low heavy metals, low sulfur content and ash content of the coal, utilization of the coal within a safe environment is feasible with just a little environment impact and make it suitable for blending with strong coking or caking properties.
\end{abstract}

Keywords: Coal, Duduguru, elemental composition and Coke

\section{Introduction}

Coal is a fossil fuel formed from the remains of plants that lived and died hundreds of millions years ago, when parts of the earth were covered with huge swampy forest. It is an organic, black combustible sedimentary rock that contains mineral or inorganic materials (Neksumi et al., 2018). It is also a heterogeneous material, whose composition changes via coalification process, the process by which plant material conversion into coal by diagenesis and metamorphism. Organic and mineral matters in coal have different surface properties, typically expressed through their hydrophobicity level (Jovica and Sanja, 2018).

Coal is the altered remains of prehistoric vegetation that originally accumulated in swamps and peat bogs, often to great depths covered by layers of water and dirt's, trapping the energy of the dead organic matter. The dead organic matter was then subjected to high temperature and pressure from the top layers (Bizualem and Busha, 2017).

The degree of transformation occurred by a coal as it matures from peat to anthracite is known as coalification. According to Mahapatra (2015), coalification has an important bearing on coal's physical and chemical characteristics and is referred to as a 'rank' of the coal. Also, the main factors in examining coal quality are coal rank and determined by the degree of changes the original plant material undergo. In addition, it's refers to the steps in a slow or natural process called "coalification", during which buried plant matter changes into an ever denser, drier, more carbon rich , and harder material (Schweinfurt, 2009).

Coal is the world's most abundant and widely distributed fossil fuel. It is a global industry that makes a significant economic contribution to the global economy (Bizualem and Busha, 2017). Coal was first discovered in Nigeria near Udi, by the mineral survey of southern Nigeria in 1909 and its belt spans through a considerable part of the country (Nasirudeen and Jauro, 2011). Therefore as part of the Nigerian government economic reform, the federal ministry of solid mineral's development was established and coal was listed as one of the priority minerals targeted for exploration and exploitation, for export and domestic consumption. Prior to this, its evaluation is necessary to ensure the nature and safety of its utility in the environment (Nasirudeen and Jauro, 2011, Neksumi et al., 2017).

Coal is classified into three main types, or ranks namely: lignite, bituminous, and anthracite, depending on the amounts or types of carbon it contains and the amount of heat energy it produce (Brian and Marty, 2008). Types of coal are fundamental factors that control coal characteristics such as the coking properties as well as other numerous technological applications (Ryemshak and Jauro, 2013).

It was discovered that most of Nigerian coals are sub-bituminous and lignite in rank and referred to as non- coking coal. The ability of a coal to be crumbles or forms a weakly coherent mass is known as non-coking or weakly coking coal. Therefore, to obtain a high required quality coke, coal has to undergone blending processed (Nasirudeen and Jauro, 2011, Ryemshak and Jauro, 2013). Furthermore, it is common practice to blend high volatile with low/medium volatile coals to improve the strength of the coke. Caking is the ability of a coal to melt upon heating and to form a coherent residue on cooling, and it is essential prerequisite for a coking coal that it should cake or fuse 
when heated. Thus, coals that are low in rank such as lignite, or high in rang such as anthracites do not cake and are therefore not capable of forming coke (Bruce, 2011).

Coal can be transform into metallurgical coke only if it softens to a plastic mass on carbonization, followed by decomposition, swelling and evolution of gas and finally re-solidification while gas is still evolved (Nasirudeen and Jauro, 2011). Metallurgical coke is a heterogeneous, porous, brittle solid, used primary in iron and steel production. It is a macro porous carbon material of high strength produced by carbonization of coals of specific rank or of coal blends at temperatures up to 1400k (Rymshak and Jauro, 2013, Diez, et al., 2002).

Coking coal is used primarily in the production of pig iron but substantial quantities are also utilized in the generation of electricity, industrial and domestic heating. An important function of the metallurgical coke used in the blast furnace is to support and provide proper permeability to the furnace burden which comprises iron ore, coke, limestone and other materials charged to the furnace. Coking coal is required for coke and can serve the blast furnace of Ajaokuta steel company (Ajani and Makoyo, 2008; Nasirudeen and Jauro, 2011).

If Nigerians coal deposits are examined and exploited, Nigerians economy can be diversified leading to smooth industrial and technological changes from the present petroleum-based economy. Therefore, this paper reports the production and characterization of metallurgical coke for possible industrial or domestic applications. Some parameters are used to determine the coking quality of the coal such as proximate analysis and elemental composition.

\section{Materials and methods}

\subsection{Materials}

The coal sample was obtained from the mining site at Duduguru, Obi Local Government Area of Nasarawa State, Nigeria. The samples were pulverized and sieved using a 200 mesh British Standard (B.S).

The major instruments to be used are; Leco digital balance LECO 250, Digital balance, Gray king furnace 11/81/1085, Ruhr Dilometer 205DiG, Gieseler plastometer and a phoenix furnace.

\subsection{Methods}

\subsubsection{Proximate analysis}

The proximate analyses of the coal were determined as described by (Nasirudeen and Jauro, 2011).

\subsubsection{Moisture content}

$20 \mathrm{~g}$ of the coal sample were determined by heating an air-dried at $105^{\circ} \mathrm{C}-110^{\circ} \mathrm{C}\left(221^{\circ} \mathrm{F}-230^{\circ} \mathrm{F}\right)$ under specified conditions until a constant weight is obtained. The moisture content was determined using the following formula;

Weight of moisture content $=\mathrm{Wt}_{3}-\mathrm{Wt}_{4}$

Percentage of moisture $=\frac{\mathrm{Wt}_{3}-\mathrm{Wt}_{4}}{\mathrm{Wt}_{2}} 100 \%$

Where $\mathrm{Wt}_{2}=$ weight of 1 gram of a known sample, $\mathrm{Wt}_{3}=$ weight of 1 gram of a known sample in a crucible, $\mathrm{Wt}_{4}=$ weight of a known sample remove from furnace and cool

\subsubsection{Volatile matter}

$20 \mathrm{~g}$ of the coal sample was determined by rigidly controlled standards. This involves heating the coal sample to $900 \pm 5^{\circ} \mathrm{C}\left(1650 \pm 10^{\circ} \mathrm{F}\right)$ for 7 minutes in a cylindrical silica crucible in a muffle furnace. The volatile content was determined using the formula;

Weight of volatile matter $=\mathrm{Wt}_{3}-\mathrm{Wt}_{4}$

Percentage of volatile matter $=\frac{\mathrm{Wt}_{3}-\mathrm{Wt}_{4}}{\mathrm{Wt}_{2}} 100 \%$

WhereWt $\mathrm{t}_{2}=$ weight of 1 gram of a known sample, $\mathrm{Wt}_{3}=$ weight of 1 gram of a known sample in a crucible, $\mathrm{Wt}_{4}=$ weight of a known sample remove from furnace and cool

\subsubsection{Ash content}

$20 \mathrm{~g}$ of the coal sample was heated for constant 4 hours at $825^{\circ} \mathrm{C}$ and the residue were allowed to cool for 1 hour in the desiccator. The ash content was determined using the formula;

Weight of ash content $=\mathrm{Wt}_{4}-\mathrm{Wt}_{1}$

Percentage of ash $=\frac{\mathrm{Wt}_{4}-\mathrm{Wt}_{1}}{\mathrm{Wt}_{2}} 100 \%$

Where $\mathrm{Wt}_{1}=$ weight of empty crucible, $\mathrm{Wt}_{4}=$ weight of crucible containing a known sample, $\mathrm{Wt}_{2}=$ weight of 1 gram of a known sample.

\subsubsection{Fixed carbon}

Fixed carbon in coal is the carbon that remains in the coal sample after volatile matter is driven off. The fixed carbon in the coal can be calculated as;

Percentage of fixed carbon $100 \%$ - (\% moisture $+\%$ volatile matter $+\%$ ash $)$. 


\subsubsection{Determination of the calorific value of coal}

The calorific value of the coal was carried out using the bomb calorimeter. The finely powdered sample of coal (sieved through the $90 \mu \mathrm{m}$ mesh) was weighed $1 \mathrm{~g}$ and pressed into pellets and placed into a bomb calorimeter. The machine was run for 8 minutes.

\subsubsection{X-ray fluorescence spectroscopic analysis}

A few amount of coal sample from Duduguru were separately placed in crucible and taken to furnace that will be heated for 30 minutes at $970{ }^{\circ} \mathrm{C}$ to remove moisture and other impurities.

\section{Result and discussion}

\subsection{Proximate analysis}

The results obtained from the proximate analysis shown on Table 1.

\subsection{Moisture content}

The moisture content of coal depends on the degree of maturity. These indicate that the lower the moisture content the higher the maturity, the reverse is the case. High moisture content is disadvantageous because it decreases system capacity, increases operational cost and increases plants capacity (Rymshak and Jauro, 2013; Neksumi et al., 2018). The reduction in moisture content represents a significant improvement in coal quality because moisture affects the calorific value as well as the concentration of other constituents (Nasirudeen and Jauro, 2011). Therefore Duduguru coal sample with the lower moisture content (1.86\%) may be matured coal and good advantage to industries.

\subsection{Volatile content}

It has been observed in the pass that coal with the high volatile-matter content ignite easily and is highly reactive in combustion applications. With increase in volatile matter content of coal there is a decrease in the calorific value of coal (Anudhyan, 2009). Non-coking or weakly coking coals are known to contain high volatile matter above 36\% (Oti and Eze, 2017). Therefore, Duduguru coal sample of high volatile content $(43.74 \%)$ could be utilized for combustion application very conveniently. Thus, Nigerian coals are known to contain moderate volatile matters which make them suitable for feedstock, chemical and allied industries. Volatile matter, aside from its use in coal ranking, is one of the paramount parameters use in determining their suitable application (Oti and Eze, 2017; Nasirudeen and Jauro, 2011).

Table 1: Proximate Composition of Coals Sample in Duduguru Coal Expressed in Percentage (\%)

\begin{tabular}{ll}
\hline Parameter & Weight $(\%)$ \\
\hline Moisture Content & 1.86 \\
Volatile Matter & 43.74 \\
Ash Content & 18.82 \\
Fixed carbon & 35.58 \\
Calorific Value (CV) & $5405.15 \mathrm{cal} / \mathrm{g}$ \\
\hline
\end{tabular}

\subsection{Ash content}

Ash has a significant influence on the heat transfer to the surface of the fuel, as well as the diffusion of oxygen to the fuel surface during char combustion (Bizualem and Busha, 2017) low ash is desirable because business must dispose of ash after the coal is used. This indicates that high ash content may create problem during combustion. May also, increase the formation of clinkers in the furnace hinder the reaction. The ash content said to be high when it's ranges from $28 \%$ - $40 \%$ (Aich, et al., 2020). This sample when burn would cause an increase to environmental pollution to a significant extent. It is therefore, paramount that, these coal samples be washed before being utilized by the industries. Thus, Duduguru coal sample with the low ash content may be a good metallurgical coking quality coal.

\subsection{Fixed carbon}

Coal sample is considered to have high fixed carbon if the fixed carbon exceeds $40 \%$. Thus, the fixed carbon has a direct relationship with the calorific value that is, the higher the fixed carbon the higher the calorific value (Oti and Eze, 2017). The carbon content is essential for coke making coal because it is the mass that forms the actual coke (Nasirudeen and Jauro, 2011). A minimum calorific value of $3500.00 \mathrm{cal} / \mathrm{g}$ may be good for electrical power generation (Rymshak and Jauro, 2013). Fixed carbon (33 \pm 3 ) \% was found to provide favorable combustion performance (Aich et al., 2020). Therefore, these indicate that the Duduguru coal sample with the relatively high value of carbon content $(35.58 \%)$ may be good for electrical power generation.

\subsection{Calorific value}

Table 1 shows the calorific value of the coal samples. The high calorific value of the coal indicates its heat generation and retention capacity. The reported limit for the calorific value of coal used in generating electricity from power plants is $2,700-9,500 \mathrm{kcal} / \mathrm{g}$ (Neksumi et al., 2018). Therefore, the calorific value of Duduguru coal sample fall within this range and the coal sample considered suitable as fuel for generating electricity in power plants. 
Table 2: Elemental Composition of Duduguru Coal

\begin{tabular}{|c|c|}
\hline Metallic Oxides & Percentage $(\%)$ in Ash \\
\hline $\mathrm{Al}_{2} \mathrm{O}_{3}$ & 8.20 \\
\hline $\mathrm{SiO}_{2}$ & 29.30 \\
\hline $\mathrm{P}_{2} \mathrm{O}_{5}$ & 0.85 \\
\hline $\mathrm{SO}_{3}$ & 5.10 \\
\hline $\mathrm{S}$ & 2.04 \\
\hline $\mathrm{K}_{2} \mathrm{O}$ & 1.00 \\
\hline $\mathrm{CaO}$ & 3.05 \\
\hline $\mathrm{TiO}_{2}$ & 8.62 \\
\hline $\mathrm{MnO}$ & 0.37 \\
\hline $\mathrm{V}_{2} \mathrm{O}_{5}$ & 0.41 \\
\hline $\mathrm{Fe}_{2} \mathrm{O}_{3}$ & 10.80 \\
\hline $\mathrm{Cr}_{2} \mathrm{O}_{3}$ & 0.19 \\
\hline $\mathrm{NiO}$ & 0.11 \\
\hline $\mathrm{CuO}$ & 0.21 \\
\hline $\mathrm{ZnO}$ & 0.44 \\
\hline $\mathrm{CaO}_{3}$ & 0.05 \\
\hline $\mathrm{SrO}$ & 0.01 \\
\hline $\mathrm{Y}_{2} \mathrm{O}_{3}$ & ND \\
\hline $\mathrm{ZrO}_{2}$ & 0.05 \\
\hline $\mathrm{WO}_{3}$ & 0.03 \\
\hline AV & ND \\
\hline $\mathrm{PbO}$ & 0.09 \\
\hline $\mathrm{ThO}_{2}$ & ND \\
\hline
\end{tabular}

$\mathrm{ND}=$ Not Detectable.

\subsection{X-ray fluorescence}

The result of X-ray florescence analysis on Table 2 indicates the presence of major elemental oxides of $\mathrm{A}_{2} \mathrm{O}_{3}, \mathrm{SiO}_{2}, \mathrm{Fe}_{2} \mathrm{O}_{3}, \mathrm{TiO}_{2}, \mathrm{CaO}_{\text {, }}$ $\mathrm{K}_{2} \mathrm{O}$ and total Sulphur in the coal sample. The metallic oxides in the coals constitute the mineral content in the coal samples which are usually presence as ash in coal and increase the overall heat transport in entire coal (Aich et al., 2020). The total sulfur content (2\%) obtained in this work is relatively lower compared to coal sample (3.49\%), $(6.42 \%)$, and $(7.13 \%)$ reportedly obtained from Khushab mines in Pakistan. The presence of the total Sulphur content of coals sample falls within the general Sulphur concentration of $2 \%$.

\section{Conclusion}

It could be observed from this study that Duduguru coal sample collected for the study contained low percentage of moisture and ash content, a moderate percentage of fixed carbon, high percentage of volatile and high calorific value. The Duduguru coal sample fell within the rank of moderate volatile bituminous coal based on the value of its fixed carbon, volatile matter and heating value. It was discovered that majority of Nigerian coals are bituminous (Rymshak and Jauro, 2013). Furthermore, low moisture and ash content indicate an improvement in coal's quality and coking (Nasirudeen and Jauro, 2011). Thus, Duduguru coal sample may be of good metallurgical coke quality from an industrial prospective and heat generation is to be considered. Elemental analysis shows that due to the low heavy metals, low sulfur content and ash content of the coal, utilization of the coal within a safe environment is feasible with just a little environment impact and make it suitable for blending with strong coking or caking properties.

\section{References}

[1] Aich S., Bahera D., Nandi B.K., and Bhattacharya S., (2020) Relationship between proximate ananlysis parameters and combustion behavior of high ash Indian coal. International Journal of Coal Science Technology. 7(4); 766-777 https://doi.org/10.1007/s40789-020-00312-5.

[2] Ajani O.O and Makoyo M. (2008). Assessement of Chikila Coal For Use as Metallurgical coke. Jormar 5(1 \& 2): 61-65.

[3] Anudhyan Mishra, (2009). Assessment of coal quality of Indian coals; Department of mining engineering national institute of technology Rourkela769008.

[4] Bizualem, W. and Busha, A. (2017). Physicochemical Characterization of Coal and its Alternative Use as a Source of Energy (in Case of Yaya Coal Mining Industry). Journal of Environmental Science, Toxicology and Food Technology, 11(5): 44-50 https://doi.org/10.9790/2402-1105034450.

[5] Brian,H. B. and Marty, W. I. (2008). Coal Characteristics. Indiana Center for Coal Technology Research,1-28

[6] Bruce. G. M. (2011). Introduction to coal utilization technologies. Clean coal engineering technology.

[7] Diez M.A, Alvarez R., Barriocanal C (2002). Coal for metallurgical coke production; predictions of coke quality and future requirements for cokemaking. International journal of coal geology 50; 389-412 https://doi.org/10.1016/S0166-5162(02)00123-4.

[8] Jovica, S, and Sanja, M. (2018). The Effect of Particle Size on Coal Flotation Kinetic. Physicochemical Problem of Mineral Process, 54(4): 11721190

[9] Mahapatra, D. (2015). A Review on Steam Coal-Sampling and Preparation. American International Journal of Research in Science, Technological Engineering and Mathematics. 13(1): 01-09.

[10] NasirudeenM. B. andJauro A., (2011). Quality of some Nigeria coals as Blending Stock in Metallurgical Coke Production. Journal of Minerals and Materials Characterization and Engineering, 10(1): 101-109. https://doi.org/10.4236/jmmce.2011.101007.

[11] Neksumi, M.,Rueben U.,Ayodele, A, and Maina, H.M. (2018). Studies on Elemental Composition and Guyuk Local Government,Adamawa State,Nigeria. Bayero Journal ofPre and Applied Science, 11(2): 267-273. https://doi.org/10.4314/bajopas.v11i2.37.

[12] Nyla, A.,Ijaz, A.B.,Khalid, A.,Munawar, I.,Arif, N, and Muhammad, Z.(2017). Variation in the Physicochemical Profile of Khushab Coal Under Various Environmental Conditions. Journal Environmental Studies, 27(3): 987-992. https://doi.org/10.15244/pjoes/70632.

[13] Oti Wilber J.O and Eze Ilochi Nkechinyere Olivia, (2017). Proximate analysis and ranking of a suspected sample of coal from Afikpo and Enugu. International journal of biology, pharmacy and allied science (IJBPAS), 6(2): 326-332.

[14] Ryemshak S. A. and Jauro A. (2013). Proximate Analysis, Rheological properties and Technological Applications of Some Nigerian Coals. International Journal of Industrial Chemistry, 1 (10): 2228-5547 https://doi.org/10.1186/2228-5547-4-7.

[15] Schweinfurth, S.P. (2009). An Introduction to Coal Quality,in Pierce,B.S., and DennenK.O,ads the National Coal Resource Assessment Over View U.S. Geological Survey Professional Paper.1625-F, Chapter C: 16. 